DESENVLVIMENTO
$\begin{aligned} & \text { SISTEMA } \\ & \text { E MEIO AMBIENTE }\end{aligned}$

\title{
Testing Alternative Models in Sustainability Economics: Baumol versus Georgescu-Roegen
}

\section{Testando modelos alternativos em economia da sustentabilidade: Baumol versus Georgescu-Roegen}

\author{
Nilton Bispo AMADO ${ }^{1 *}$, Carlos Germán MEZA ${ }^{1}$, Ildo Luis SAUER ${ }^{1}$ \\ ${ }^{1}$ Instituto de Energia e Ambiente (IEE), Universidade de São Paulo (USP), São Paulo, SP, Brasil. \\ *E-mail de contato: nilton@iee.usp.br
}

Artigo recebido em 4 de outubro de 2016, versão final aceita em 16 de outubro de 2017.

ABSTRACT: Given the ubiquitous nature of the laws of thermodynamics, it would be reasonable to expect that the divergence between strong and weak sustainability could be subjected to critical tests. That is, it should be possible to use the neoclassical production theory and the laws of thermodynamics to generate predictions able to question the empirical adequacy of the neoclassical research program in terms of sustainability. However, the current state of the debate normally suggests the opposite, that is, the currently available evidence is not sufficient to build refutations. Contrary to this prognosis, we argue that it is possible to build critical tests to evaluate the models in dispute using evidence already available. However, such a construction requires that the analysis of the sustainability be not restricted to the type of evidence traditionally used by such models. We argue that alternative theories must be explicitly used to give meaning to new types of evidence. Without the explicit mobilization of alternative theories to evaluate new types of evidence, critics of the orthodox theory dwell on an epistemological trap, in which the questioned research program determines what is or what is not scientifically meaningful. To illustrate the prospects of the methodological proposal presented here, we apply this approach to a particular neoclassical model - the Baumol's model -, which explicitly supports the ability to indefinitely continue the trajectory of economic growth triggered by the Industrial Revolution. The results refute the tested neoclassical model, demonstrate the need to distinguish between intensive and extensive substitution of natural resources, and corroborate the Geogescu-Roegen fund-flow model.

Keywords: testability; sustainable development; economic growth; natural resources; energy.

RESUMO: Dado o caráter ubíquo das leis da termodinâmica, seria razoável esperar que a divergência entre sustentabilidade forte e sustentabilidade fraca pudesse ser submetida a testes críticos. Ou seja, deveria ser possível usar a teoria 
de produção neoclássica e as leis da termodinâmica para gerar previsões capazes de questionar a adequação empírica do programa de pesquisa neoclássico no que se refere à sustentabilidade. Entretanto, o estado atual do debate normalmente sugere o oposto, isto é, a evidência atualmente disponível não é suficiente para construir refutações. Contrariamente a esse prognóstico, argumentamos que a evidência atualmente disponível permite construir testes críticos potencialmente capazes de refutar os modelos em disputa. Entretanto, tal construção requer que não se restrinja a análise da sustentabilidade ao tipo de evidência tradicionalmente usada por tais modelos. Defendemos que teorias alternativas devem ser explicitamente empregadas para dar significado a novos tipos de evidência. Sem a explícita mobilização de teorias alternativas para avaliar novos tipos de evidência, críticos da teoria ortodoxa ficam presos em uma armadilha epistemológica, em que o programa de pesquisa questionado determina o que é ou não cientificamente significativo. Para exemplificar as perspectivas da proposta metodológica aqui apresentada, aplicamos essa abordagem a um modelo neoclássico particular, o modelo de Baumol, no qual se defende explicitamente a possibilidade de continuar indefinidamente a trajetória de crescimento econômico desencadeada pela Revolução Industrial. Os resultados refutam o modelo neoclássico testado, demonstram a necessidade de distinguir a substituição intensiva da extensiva de recursos naturais e corroboram o modelo fundos-fluxos de Geogescu-Roegen.

Palavras-chaves: testabilidade; desenvolvimento sustentável; crescimento econômico; recursos naturais; energia.

\section{Introduction}

It is well known that there is a profound divergence between neoclassical and ecological economics concerning the role of natural resources in the production system ${ }^{1}$. Neoclassical economists argue that from the economic point of view there is no difference between natural capital and other types of capital, and that it is generally possible to substitute manufactured capital for natural capital. Meanwhile, ecological economists, based on thermodynamic considerations, argue that natural capital and manufactured capital are fundamentally complements and only marginally substitute (Daly, 1994, p. 25). While neoclassical economists view natural capital from a perspective of monetary or monetizable values, ecological economists perceive natural capital as low entropy resources, without which no physical system in general and no economic system in particular can operate.

The differences between these visions ${ }^{2}$ not surprisingly lead to radically different evaluations of what is conceivable in terms of sustainability. While ecological economics considers that there are severe

\footnotetext{
${ }^{1}$ See, for instance, the debate between Daly (1997a; 1997b) and Solow (1997) at the special edition of Ecological Economics dedicated to Georgescu-Roegen. For a systematic exposition of this dissent, see Neumayer (2003).

${ }^{2}$ We use the term as proposed by Schumpeter (1949, p. 350): "First, that perception of a set of related phenomena is a prescientific act. It must be performed in order to give to our minds something to do scientific work on - to indicate an object of research - but it is not scientific in itself. But though prescientific, it is not preanalytic. It does not simply consist in perceiving facts by one or more of our senses. These facts must be recognized as having some meaning or relevance that justifies our interest in them and they must be recognized as related - so that we might separate them from others - which involves some analytic work by our fancy or common sense. This mixture of perceptions and prescientific analysis we shall call the research worker's Vision or Intuition."
} 
restrictions to continue increasing the productivity of natural resources, neoclassical economics assumes that the productivity of natural resources can continue due to technological developments. Actually, neoclassical economics has argued that under certain plausible assumptions it is possible to keep sustaining economic growth trajectories ${ }^{3}$. The thesis that we can prolong indefinitely economic growth trajectories is, of course, a very strong proposition, but it is simultaneously the logical consequence of both the neoclassical theory and the usual empirical indicators used by orthodox economic theory. Given the importance of this thesis in both political and economic terms, one would expect its systematic scrutiny by the analysis of neoclassical models that are used to support it. Moreover, considering the ubiquitous nature of the laws of thermodynamics, it would be expected that propositions that suggest apparent conflict with the implications of the laws of thermodynamics could be somehow susceptible to empirical evaluation. Nevertheless, in the debates about the issue, it is generally assumed that critical tests of the neoclassical theory are not possible or that they will be only possible in a distant future ${ }^{4}$.

This article uses a specific neoclassical model to demonstrate that it is possible to formulate an empirical critique of the neoclassical theory. We argue that it is possible to extend and deepen the analysis if we do not restrict ourselves to the typical neoclassical evidence, such as price or elasticity of substitution. To exemplify this methodological proposal, we critically evaluate a model proposed by Baumol (1986), in which he defends the possibility of indefinitely prolonging the economic growth trajectory unleashed by the Industrial Revolution.

Taking neoclassical production theory to its ultimate consequences, Baumol (1986) advocates the possibility of continuous expansion of finite resources. Baumol (1986, p. 167) also links this possibility to the following interpretation of the economic growth trajectory triggered by the Industrial Revolution:

The received wisdom of environmental literature gives prominence to the fact that the Earth is a planet whose contents are finite and whose resources, if used

\footnotetext{
${ }^{3}$ According to Solow (1974, p. 11, author's emphasis): "In the simplest, most aggregate, model of a resource-using economy one can prove something like the following: if the elasticity of substitution between exhaustible resources and other inputs is unity or bigger, and if the elasticity of output with respect to reproducible capital exceeds the elasticity of output with respect to natural resources, then a constant population can maintain a positive constant level of consumption per head forever. This permanently maintainable standard of living is an increasing, concave, and unbounded function of the initial stock of capital. So the drag of a given resource pool can be overcome to any extent if only the initial stock of capital is large enough. On the other hand, if the elasticity of substitution between natural resources and other inputs is less than one, or if the elasticity of output with respect of resources exceeds the elasticity of output with respect to reproducible capital, then the largest constant level of consumption sustainable forever with constant population is - zero. We know much too little about which side of that boundary the world is on - technological progress aside - but at least the few entrails that have been read seem favorable." About that "few entrails", Solow cites the following reference: Nordhaus, W. D.; Tobin, J. Is economic growth obsolete? In: National Bureau of Economic Research, Economic Growth, 50th Anniversary Colloquium V, New York, 1972.

${ }^{4}$ For instance, Neumayer (2003, p. 88) writes: "Chapter 3 has tried to assess the validity of the opposing claims of WS [Weak Sustainability] and SS [Strong Sustainability] with respect to the substitutability of natural capital. The conclusion that arises from the analysis is that both paradigms are non-falsifiable under scientific standards. Both rest on assumptions as well as hypotheses and claims about (distant) future that are non-refutable. That does not mean, of course, that either paradigm is nonsensical. Both have some theoretical plausibility as well as empirical evidence in their support. But as neither paradigm can be refuted it does mean that science can give no unambiguous answer which paradigm of sustainability society should follow if it is committed to SD [Sustainable Development]".
} 
continuously, must ultimately be exhausted. Taken in its obvious sense this observation is as undeniable as it is trivial. However, as will be shown in this note, there is a sense far more significant for the social welfare in which this need not be true. On the contrary, measured in terms of their prospective contribution to human welfare the available quantity of these exhaustible and unreproducible resources may arise unceasingly year after year.

Rather than approaching exhaustion with increased use, their effective inventories may actually be growing and they never come anywhere near disappearance. In short, our society's growing per capita output, rather than constituting a case of profligacy in which society lives off its capital, may in fact involve what amounts to not saving of unreproducible resources, so that their effective stocks are constantly expanded by the same family of developments that underlie the growth in real per capita income since the Industrial Revolution. Moreover, I will provide evidence suggesting that this is no mere abstract possibility but is rather something that may actually be happening now.

Baumol's (1986) view is particularly useful as it explores in a simple and straightforward manner assumptions tacitly embraced not only by neoclassical economists, but also by the economic order triggered by the Industrial Revolution. Although Baumol's model (1986) was published more than 30 years ago, it remains an important reference to address neoclassical thinking about the relation between natural resources, economic growth and technological innovation (Earp \& Romeiro, 2015;
Kalimeris et al., 2014; Chen et al., 2017; Carmona et al., 2017; Bithas \& Kalimeris, 2016). Moreover, the premise that there are almost no limits for scientific/technological progress to increase efficiency in the use of natural resources has been endorsed in the core of the neoclassical mainstream of environmental economics (Romeiro, 2012, p. 73). Indeed, theoretically, in the perspective of neoclassical research program there may well exist a growth economy based only on "information" or "knowledge".

We claim that if there is some inconsistency in neoclassical analysis, it cannot be a mere logical contradiction, but rather an inconsistency between the theory and the object this theory is supposed to describe. Rather than using intuitions provided by the laws of thermodynamic to reject the possibility of perpetuating an indefinitely economic growth from finite resource bases, it can be more scientifically enlightening to compare the empirical adequacy of specific models used to defend perpetual economic growth thesis in relation to specific evidence This comparison is particularly useful when the models imply opposite consequences, not because refutations irreversibly show which of theoretical perspectives is scientifically more consistent, but because refutations are informative even when they are not definitive (Earp \& Trafimow, 2015) ${ }^{5}$.

However, to refute an existing theory, is essential to have an alternative theory capable of giving meaning to empirical evidence and able to refute the accepted theory ${ }^{6}$. Thus, the attempt to

\footnotetext{
${ }^{5}$ They are also informative even when considering, as in our case, that the transition from one research program to another does not only depend on refutations, although they are an important part of the transition process.

${ }^{6}$ On this point, see Feyerabend (1965). The author argues that in the absence of an alternative theory, facts that refute the accepted theory stay hidden. "Now if it is true, as was argued in the last section, that many facts become available only with the help of alternatives, then the refusal
} 
disprove a mainstream theory is, especially when it is extended to consider new types of evidence, a process in which concepts and empirical evidence become - hitherto considered meaningless by the practitioners of the mainstream framework - operational and demonstrate their significance to the scientific community. We use the criticism of the model proposed by Baumol (1986) to exemplify that approach ${ }^{7}$.

First, we present Baumol's (1986) contention that continuous expansion on finite resources is possible. Then we develop a new direct implication of Baumol's (1986) model: the thesis of the decreasing use of natural resources. After exposing this empirical prediction of Baumol (1986)'s model, we confront the neoclassical interpretation of the facts relating to the productivity of natural resources with an alternative interpretation: the Georgescu-Roegen (1971; 1984)'s fund-flow approach denies the thesis of the decreasing use of natural resources and supports the need to distinguish between intensive and extensive substitution of natural resources. Having two theoretical interpretations generating specific and opposite empirical implications (increasing inflows versus decreasing inflows), we confront these models with the available evidence. We make this confrontation using the Spearman's rank correlation coefficient in the total primary energy consumption per capita of 153 countries. The test results generally deny the possibility of continuous expansion on finite resources, corroborates the fund-flow approach proposed by Georgescu-Roegen (1971; 1984) and justifies the distinction between intensive and extensive substitution of natural resources.

\section{Baumol's model and a new type of evidence}

Baumol (1986) argues that if the economic mechanisms by which a production system compensates for physical exhaustion are not adequate, a trend of increasing relative prices involving these natural resources should ensue. How can the scarcity of natural resources be increasing if the prices of most major minerals have such long histories of falling (Baumol, 1986, p. 168-169)? Although it may be reckless to consider prices as reliable indicators in this context, the evidence offered by them cannot simply be ignored. At least, they indicate that some feedback mechanism has caused a persistent drop in the prices of these production factors. Baumol (1986) presented an interpretation of this mechanism by means of a model. This model is based on the following definitions (Baumol, 1986, p. 173):
$\mathrm{R}_{\mathrm{t}}=$ The usable quantity of resource remaining on the planet in period $t$.
$\mathrm{Vt}=$ The quantity used up during period $\mathrm{t}$.
$\mathrm{D}_{\mathrm{t}}=$ The quantity demanded for industrial and con- sumption purposes in that period.

to consider them will result in the elimination of potentially refuting facts. More specifically, it will eliminate facts whose discovery would show the complete and irreparable inadequacy of the theory". (Feyerabend, 1965, p. 177, author's emphasis)

${ }^{7}$ In this article, we raise strong objections to Baumol (1986). However, although we strongly disagree with Baumol (1986)'s conclusions, we would like to emphasize that we consider that his procedure is highly laudable in scientific terms, for developing the logical implications of the assumptions and relations of the research program he advocates, even when they enter in conflict with what is suggested by other fields of knowledge (laws of thermodynamics). In doing so, Baumol (1986) rejects ad hoc compromises, which increases clarity and creates conditions for theoretical and empirical critique of the accepted theory and, therefore, for scientific progress. 
$E_{t}=$ The effective stock of the resource in period $t$. $\mathrm{M}_{\mathrm{t}}=\mathrm{R}_{\mathrm{t}} / \mathrm{E}_{\mathrm{t}}=$ The ratio of total stock to effectively usable stock, i. e., $1-1 / \mathrm{M}_{\mathrm{t}}$ is the proportion that will be wasted during use.

$a_{t}=\left(D_{t}-D_{t-1}\right) / D_{t-1}=$ The relative increase in quantity of resource demanded during period $t$.

According to Baumol (1986, p. 174), the physical exhaustion of resources requires that:

$$
\mathrm{R}_{\mathrm{t}+1}=\mathrm{R}_{\mathrm{t}}-\mathrm{V}_{\mathrm{t}}
$$

Baumol (1986, p. 174) assumes that the degree of inefficiency in resource use does not depend on the scale at which resources are used. Based on this hypothesis, the definition of $\mathrm{M}_{\mathrm{t}}$ for the period of time t yields:

$$
\mathrm{V}_{\mathrm{t}}=\mathrm{M}_{\mathrm{t}} \mathrm{D}_{\mathrm{t}}
$$

After formally investigating the uniqueness of the solutions, Baumol (1986, p. 176) uses equations 2.1 and 2.2 to demonstrate the following propositions:

Proposition 1. There exist consistent time paths involving monotonic depletion of the available quantity of physical resource, $\mathrm{R}_{\mathrm{t}}$ and monotonic reductions in the inefficiency coefficient, which lead to monotonic and perpetual increases in the effective inventory of the resource, $\mathrm{E}_{\mathrm{t}}$.

Proposition 2. So long as $\mathrm{M}_{t}$ possesses a lower bound $\mathrm{m}^{*}$, then $\mathrm{E}_{\mathrm{t}}$ must be constrained by a finite upper bound and $\mathrm{D}_{\mathrm{t}}$ must ultimately fall below any preassigned lower bound.

The idea behind Proposition 1 is quite simple.
To increase the effective stock of a resource, considering its physical deterioration over time, it is only necessary that technological innovations allow for economic efficiency to increase faster than the rate of physical deterioration. In this case, using the definitions given before, it is obtained the following equation:

$$
M_{t}=R_{t} / E_{t}=>E_{t}=R_{t} / M_{t}
$$

Even with the physical deterioration of resources (that is, decreasing $\mathrm{R}_{\mathrm{t}}$ ), it is clear from the equation that actual stock increases if $M_{t}$ inefficiency falls faster than $\mathrm{R}_{\mathrm{t}}$. Operationally, this procedure assumes that economic efficiency and physical efficiency are independent variables. Further on, we will discuss this premise again.

Proposition 2 seeks to incorporate thermodynamic constraints. It is known that the physical efficiency of real systems cannot be increased indefinitely. In order to incorporate this restriction, Baumol (1986) assumes that inefficiency has an absolute floor $\mathrm{m} *$, which cannot be lowered by any technological innovation. From Baumol's (1986) perspective, this limit defines the domain of existence of all conceivable technologies. Assuming the existence of this limit and recognizing that the amount of physical $R_{t}$ is finite, Baumol (1986, p. 176) demonstrates that in a viable perpetual economic growth path the effective demand $\mathrm{D}_{t}$ for natural resources is always superiorly limited. In short, even with absolute limits on physical efficiency, the possibility of continuing expansion of finite resources may be perpetual if the growth rate in economic efficiency is greater than the rate of physical deterioration.

Actually, Baumol (1986) is just following the 
neoclassical tradition of considering the concrete material basis as a homogeneous whole that can be freely mobilized according to the convenience of firms. In this tradition, the role of science and technology is to ensure production factors homogeneity ${ }^{8}$, while the role of economics is to study the best way to efficiently allocate these "homogeneous" factors.

It is possible to use Baumol (1986)'s model to extract a falsifiable proposition. According to Baumol definitions:

$$
\mathrm{R}_{\mathrm{t}+1}=\mathrm{R}_{\mathrm{t}}-\mathrm{V}_{\mathrm{t}}
$$

In each period $t, V_{t}$ resources are consumed. Therefore, after each period the usable quantity of resource remaining on the planet $\left(R_{t}\right)$ is diminished by the quantity $\mathrm{V}_{\mathrm{t}}$. The Equation 2.1 exposes this fact affirming how much resources remain to be explored in the following period $(\mathrm{t}+1)$. Equation 2.1 can be rewritten to express $V_{t}$ resources consumed in function of remaining resources. Thus, the $\mathrm{V}_{t}$ resources consumed are equal to:

$$
\mathrm{V}_{\mathrm{t}}=\mathrm{R}_{\mathrm{t}}-\mathrm{R}_{\mathrm{t}+1}
$$

Baumol (1986, p. 176) assumes that the rate of physical degradation of resources follows an exponental trend, according to the following equation:

$$
\mathrm{R}_{\mathrm{t}}=\mathrm{R}\left(1+\mathrm{be}^{-\mathrm{rt}}\right) \text { with } \mathrm{b}, \mathrm{r}>0
$$

According to Baumol (1986)'s definitions, $\mathrm{R}_{\mathrm{t}}$ represents the usable quantity of resource remaining on the planet in period t. Baumol (1986) further assumes that this stock resources starts from an initial total quantity $\mathrm{R}$ and degrades by decaying exponentially, as indicated by Equation 2.4.

Equation 2.4 indicates the remaining usable resources at period $t$. Then, the usable resources at period $(\mathrm{t}+1)$ are:

$$
\mathrm{R}_{\mathrm{t}+1}=\mathrm{R}\left(1+\mathrm{be}^{-\mathrm{r}(\mathrm{t}+1)}\right)=>\mathrm{R}_{\mathrm{t}+1}=\mathrm{R}\left(1+\mathrm{be}^{-\mathrm{rt}-\mathrm{r}}\right)
$$

Thus, by substituting equations 2.4 and $2.4 \mathrm{a}$ into the Equation 2.1a:

$$
\begin{aligned}
\mathrm{V}_{\mathrm{t}} & =\mathrm{R}\left(1+\mathrm{be}^{-\mathrm{rt}}\right)-\mathrm{R}\left(1+\mathrm{be}^{-\mathrm{rt}-\mathrm{r}}\right) \\
\mathrm{V}_{\mathrm{t}} & =\mathrm{R}+\mathrm{Rb} \mathrm{e}^{-\mathrm{rt}}-\mathrm{R}-\mathrm{Rbe}^{-\mathrm{rt}-\mathrm{r}} \\
\mathrm{V}_{\mathrm{t}} & =\mathrm{R} b \mathrm{e}^{-\mathrm{rt}}-\mathrm{Rbe}^{-\mathrm{rt}-\mathrm{r}} \\
\mathrm{V}_{\mathrm{t}} & =\mathrm{Rbe}^{-\mathrm{rt}}\left(1-\mathrm{e}^{-\mathrm{r}}\right) \\
\mathrm{V}_{\mathrm{t}} & =\mathrm{Rbe}^{-\mathrm{rt}}\left(1-\mathrm{e}^{-\mathrm{r}}\right) \times\left(\mathrm{e}^{\mathrm{r}} / \mathrm{e}^{\mathrm{r}}\right) \\
\mathrm{V}_{\mathrm{t}} & =\mathrm{Rbe}^{-\mathrm{rt}-\mathrm{r}}\left(\mathrm{e}^{\mathrm{r}}-1\right)
\end{aligned}
$$

Taking the derivate of Equation 2.1c, we have:

$$
\mathrm{dV}_{\mathrm{t}} / \mathrm{dt}=-\mathrm{rRbe} \mathrm{e}^{-\mathrm{rt}-\mathrm{r}}\left(\mathrm{e}^{\mathrm{r}}-1\right)
$$

Now, it is known that $\mathrm{e}^{\mathrm{r}}>1$ for all $\mathrm{r}>0$. By considering that $\mathrm{r}, \mathrm{R}, \mathrm{b}>0$, it is clear that the derivative of the $\mathrm{V}_{\mathrm{t}}$ resources consumed in relation to time $\left(\mathrm{dV}_{\mathrm{t}} / \mathrm{dt}\right)$ must be a negative quantity:

\footnotetext{
${ }^{8}$ For instance, Barnett \& Morse (1963, p. 11, our emphasis) affirm that "A limit may exist, but it can be neither defined nor specified in economic terms. Flexibility, not rigidity, characterizes the relationship of modern man to the physical universe in which he lives. Nature imposes particular scarcities, not an inescapable general scarcity. Man is therefore able, and free, to choose among indefinitely large number of alternatives. There is no reason to believe that these alternatives will eventually reduce to one that entails increasing cost - that it must sometime prove impossible to escape diminishing quantitative returns. Science, by making the resource base more homogeneous, erases restrictions once thought to reside in the lack of homogeneity".
} 


$$
\mathrm{dV}_{\mathrm{t}} / \mathrm{dt}<0
$$

That is, the conditions stipulated by Baumol (1986)'s model generate as logical necessity a downward trend in the quantity used up during each period t. Thus, the viability of current trajectories should be assessed taking into account the trajectory of natural resources prices - which importance is emphasized by Baumol (1986) and neoclassical economists in general -, and also the trends in the quantity used up during each period $t$ for each production cycle $\left(\mathrm{dV}_{\mathrm{t}} / \mathrm{dt}<0\right)$.

\section{Two alternative descriptions of efficiency gains}

Baumol (1986) considers that thermodynamic constraints were completely incorporated by the recognition of a lower limit $\left(\mathrm{m}^{*}\right)$ for physical inefficiency. However, a comparison between his neoclassical model and the Georgescu-Roegen's vision ${ }^{9}$ raises doubts. For instance, contrary to the neoclassical conception, in the model proposed by Georgescu-Roegen (1984) it is not possible continuing to increase resource productivity while the physical use of resources continuously decreases. While economic efficiency and physical availability are taken as independent variables in Baumol's (1986) model, in Georgescu's model (1984) it is argued that the economic efficiency with which na- tural resources are used usually depends on the physical availability of natural resources ${ }^{10}$. Georgescu $(1971 ; 1984)$ defends an economic conception that incorporates not only absolute limits for physical efficiency of real systems, but also restrictions on how trajectories of efficiency gains can be built.

Neoclassical economics believes that the success of self-regulating markets and technological innovation in providing natural resources has been robust enough to disregard concrete material differences among production factors, and the decreasing long-term prices of natural resources are considered the main indicator of this success. In contrast, Georgescu-Roegen $(1971 ; 1984)$ considers that the qualitative difference among production factors is higher than the neoclassical models assume and also more important for economic analysis than economic orthodoxy admits. This qualitative difference is particularly emphasized by his fund-flow approach (Georgescu-Roegen, 1971; 1984). In his analysis, flows from stocks and services propitiated by funds provide the economic benefits we have been extracting from nature.

For Georgescu-Roegen (1971; 1984), both stocks and funds require the mobilization of flows in their constitution and operation. In his analysis, it is particularly important the fact that flows necessarily involve a qualitative transformation of production factors. In this perspective, the homogeneity of the production factors presupposed by neoclassical models is, in fact, one of the consequences of active

\footnotetext{
${ }^{9}$ See footnote 2 .

${ }^{10}$ Georgescu-Roegen (1984, p. 29): "The special stumbling block thus comes to the surface: from all we know, to tap nature for her treasures (fossil fuels and even waterfalls) 'tools' of greater and greater dimensions had to be used. More efficient machines need a greater amount of matter and energy to go through the whole economic process. A thermonuclear reactor may very well be as great as the whole Manhattan". For Georgescu-Roegen (1984), the computer seems to be the only possible exception to the rule that more efficient engines operate with higher total amounts of matter and energy.
} 
mobilization of flows from stocks, which is greatly accelerated since the Industrial Revolution.

Furthermore, there are fundamental differences between stocks and funds (Georgescu-Roegen, 1971, p. 226-227):

The difference between the concept of stock and that of fund should be carefully marked, lest the hard facts of economic life be distorted at everyone's expense. If the count shows that a box contains twenty candies, we can make twenty youngsters happy now or tomorrow, or some today and others tomorrow, and so on. But if an engineer tells us that one hotel room will probably last one thousand days more, we cannot make one thousand roomless tourists happy now. We can only make one happy today, a second tomorrow, and so on, until the room collapses. Take also the case of an electric bulb which lasts five hundred hours. We cannot use it to light five hundred rooms for an hour now. The use of a fund (i.e., its "decumulation") requires a duration. Moreover, this duration is determined within very narrow limits by the physical structure of the fund. We can vary it only little, if at all.If one wishes to "decumulate" a pair of shoes, there is only one way open to him: to walk until they become waste. In contrast with this, the decumulation of a stock may, conceivably, take place in one instant, if we wish so.

That is, the benefits from a stock can be instantly consumed or spread out over a time interval, according to the user convenience, while the benefits from a fund must be used in duration times whose limits are determined by the physical structure of the fund. Additionally, for the fund to continue to operate viewed only in its "original and indestructible powers" (Georgescu-Roegen, 1971, p. 216), it is necessary to allocate a portion of the available flows and work time to restore the productive capacity of the fund.

Labour and renewable energy are resources that can continue to be used for a presumably unlimited period. However, throughout their life cycles, they will impose periods of idleness. The employee's use rate is limited by both social and physical factors; the use rate of renewable resources is limited by the system regenerative capacity and also by climatic factors. In both cases, the benefits from the production factors are necessarily and recurrently interrupted by periods of idleness. That is, labour and renewable resources are resource funds.

In fact, in Georgescu-Roegen (1971; 1984)'s formulation, an important part of the history of productivity increases, which we have observed since the Industrial Revolution cannot be attributed in any sense to human ingenuity or institutional changes. In the perspective of Georgescu-Roegen (1971; 1984)'s formulation, the flows provided by natural resource stocks have been an essential component of productivity gains that we have observed in the operation of all funds since the Industrial Revolution. As the author builds his vision inspired by the laws of thermodynamics, this point can be made clearer by presenting a brief description of how the efficiency of ideal heat engines can be improved.

Heat engines can do useful work only by transferring some heat from a hot reservoir to a cold one. It is known that the efficiency $(\eta)$ of a Carnot's heat engine is given by:

$$
\eta=1-\left(\mathrm{T}_{\text {cold }} / \mathrm{T}_{\text {hot }}\right)
$$

If we suppose that the temperature of the cold reservoir $\left(T_{\text {cold }}\right)$ is always the environment temperature, then we have that the higher the temperature of the hot reservoir $\left(\mathrm{T}_{\text {hot }}\right)$, the greater the efficiency of the heat engine. It is also true that the higher the total fuel available, the higher the temperature the 
hot reservoir may operate. That is, the greater the availability of fuel, the greater the efficiency with which the machine can operate even if there has been no improvement in the construction or operation of the machine.

Heat engines illustrate clearly that total fuel consumption can increase while consumption per unit of useful work decreases. In fact, the thought experiment in which Carnot sets the limits to heat engines efficiency can be read as a demonstration that the possibility of further increasing efficiency depends on access to increasing amounts of fuel, and not only on the ingenuity of engineers. In this context, it is appropriate to distinguish between intensive (useful work per unit of fuel) and extensive (total fuel consumption) variables, since increased efficiency is not necessarily correlated to lower total fuel consumption, on the contrary. We use the term "intensive variable" to refer to a ratio between two total quantities, and the term "extensive variables" to refer to a total quantity of the system. Thus, extensive variables are always a quantity whose observation necessarily incorporates any changes in the system dimensions. The total energy consumption depends on the size of the economic system (including physical), while energy intensity may decrease while simultaneously the system size increases ${ }^{11}$.

Contrary to the situation outlined in the case of the heat engines, in neoclassical economic analysis there is no distinction between intensive and extensive variables. Furthermore, it is assumed that only efficiency indicators, which correspond to a specific kind of intensive variables, are relevant for characterizing the dynamics of resource utilization. Herein lies the radical difference between neoclassical and fund-flow approaches.

As it was mentioned before, the neoclassical model assumes that science and technological development has ensured virtually absolute homogeneity among production factors. This uniformity in turn ensures that substitution is, among production factors, only a matter of incentives and technological innovation. In this context, if there are absolute restrictions on the use of specific production factors, what matters in economic terms is how many units of other resources are needed and what are the relative prices of the production factors involved.

In the fund-flow approach, the problem arises otherwise. Not only intensive substitution (decrease in fuel consumption for producing each unit of economic value) can occur without extensive substitution (decrease in the total fuel consumption), as extensive complementarity (increase in the total fuel consumption) can be a cause of intensive substitution, analogously as it occurs in heat engines. In this model, while the supplies last, the use of increasing amounts of flows from fossil stocks allows to sustain economic growth with intensive substitution trajectories. However, intensive substitution cannot

\footnotetext{
${ }^{11}$ We do not explore all the implications of the distinction between intensive and extensive variables, although our use is following a thermodynamic inspiration (Sontag et al., 2003, p. 17): "Thermodynamic properties can be divided into two general classes, intensive and extensive properties. An intensive property is independent of the mass; the value of an extensive property varies directly with mass. Thus, if a quantity of matter in a given state is divided into two equal parts, each part will have the same intensive properties as the original and half the value of extensive properties. Pressure, temperature, and density are examples of intensive properties. Mass and total volume are examples of extensive properties. Extensive properties per unit of mass, such as specific volume, are intensive properties". For a discussion of the importance of distinguishing intensive and extensive variables when analyzing complex adaptive systems, see Giampietro \& Mayumi (2008).
} 
increase indefinitely without resorting to extensive complementarity of flows.

Although the laws of thermodynamics are useful in providing insights, their relevance to the physical world is not by itself guarantee that these laws are useful for economic theory. The question of which approach is the most adequate is ultimately an empirical question. To move forward in terms of scientific understanding of the problem, it is necessary to compare the empirical adequacy of the models to explain the substitution of natural resources. The inequality $\mathrm{dVt} / \mathrm{dt}<0$ allows such comparison. If we get $\mathrm{dVt} / \mathrm{dt}<0$, the neoclassical model should be considered empirically adequate; if we obtain $\mathrm{dVt} / \mathrm{dt}>0$, this indicates the relevance of Georgescu-Roegen's approach and the need to use systematically the distinction between intensive and extensive substitutions in economic analysis of the trajectories of the use of natural resources.

\section{Using natural resource inflows as evidence}

We evaluate the discussed models using Spearman's rank correlation coefficient to test the existence of a decreasing trend on total primary energy consumption per capita (millions of BTU per person). The Spearman's rho test is a rank-based non-parametric statistical test that can be used to detect monotonic trend in a time series. The idea behind the test is the following: each variable is ranked separately from the lowest to highest (e.g. 1, 2, 3 etc.) and the difference between ranks for each data pair is recorded. If the data are correlated, then the sum of the square ranks will be small. The magnitude of the sum is related to the significance of the correlation (Gauthier, 2001). The Spearman's rank correlation is calculated according to the following equation:

$$
r_{s}=\frac{\left(1-6 * \sum \mathrm{d}_{i}^{2}\right)}{n^{3}-n}
$$

In which $d_{i}$ is the difference between ranks for each data pair and $n$ is the number of data pairs. Given a sample data set of total primary energy consumption per capita by year $\left\{\mathrm{X}_{\mathrm{i}}, \mathrm{i}=1980,1981, \ldots\right.$, $\mathrm{n}$ \}, the null hypothesis $\mathrm{H}_{0}$ of the Spearman's rank correlation test against the trend test is that all the $\mathrm{X}_{\mathrm{i}}$ are independent and identically distributed. The alternative hypothesis is that $\mathrm{X}_{\mathrm{i}}$ increases or decreases with $\mathrm{i}$, that is, there is a trend ${ }^{12}$.

In our study, we apply the test for 49 African countries, 22 Asian countries, 4 Oceanian countries, 3 North American countries, 22 Central and South American countries, 25 European countries, 13 Middle East countries, 11 former U. S. S. R. countries and 4 former Yugoslavia countries (excluding Serbia and Montenegro), totalling 153 countries. Countries with less of 1 million inhabitants were excluded from the analysis. The analysis period is from 1980 to $2011(n=32)$, except for former U. S. S. R., Yugoslavia countries $(1992-2011 ; n=20)$ and Germany (1991-2011; $n=21)$. The analysis periods were determined according to the availability in the used database when performing the test. The energy data were collected from EIA (2015).

Strictly speaking, the test of Equation 2.6 should be applied to countries with growing per

\footnotetext{
${ }^{12}$ See Yue et al. [2002], p. 270, for complete mathematical and statistical details, or Gauthier [2001] and Conover (1980) for examples of application.
} 
capita output during the analysis period ${ }^{13}$. Thus, for countries that exhibited a decreasing trend on total primary energy consumption per capita, it was also applied the Spearman's correlation coefficient to detect and exclude countries with downward trends in GDP per capita (1990 International Geary-Khamis dollars). The GDP data was collected from Angus Maddison's research homepage at the University of Groningen Department of Economic ${ }^{14}$.

It is observed energy consumption per capita instead of absolute energy consumption because, otherwise, the increases in energy consumption could be attributed to increases in population. An important limitation of this test is that the indirect consumption of energy is not investigated. Thus, the analysis presented here does not allow us to reject the hypothesis that countries that pass the test do so by relying on the transfer of dirty activities to other countries. The energy embodied in goods and services purchased from other countries must also be investigated, so as to conclusively verify the test of Equation 2.6. In any case, the test works as a first check such that countries that do not pass it do not show sustainable economic growth trajectories ${ }^{15}$.

The same test can be applied to any other natural resources. It is possible to notice that for the analysis of Equation 2.6 it is irrelevant to investigate the type of energy sources, i.e., whether or not these sources are renewable. From the point of view of testing Baumol's model (1986), all that matters is to determine if we have a decreasing trend in the quantity of used resources in an economic growth path.

Setting the significance level at 5\% (critical values of the Spearman's ranked correlation coefficient are $\rho=-0.295$ for $n=32, \rho=-0.378$ for $n=20$, and $\rho=-0.368$ for $n=21$ ), the results obtained lead us to reject the hypothesis of an overall downward trend on total primary energy consumption per capita for 124 out of the 153 countries. Out of the 29 countries with downward trends on total primary energy consumption per capita, 20 countries did not maintain economic growth trends (including 14 African countries). Thus, just 9 countries out of 153 (5.2\%), of which only Germany belongs to the G-20 major economies, have shown energy consumption per capita downward trends and, simultaneously, economic growth trajectories as it should be, according to Equation 2.6 $6^{16}$. Therefore, generally the observed trends are the reverse of those predicted by Baumol's model (1986).

Indeed, these results just confirm the energy per capita consumption trends observed globally after the Industrial Revolution, as shown in Figure 4.1, which was taken from Grübler (2005, p. 166).

Figure 4.1 illustrates that, since the Industrial Revolution (more than 200 hundred years ago), manufactured capital and technological innovation have not been used to replace natural resources, but

\footnotetext{
${ }^{13}$ Baumol (1986, p. 167, our emphasis): "In short, our society's growing per capita output, rather than constituting a case of profligacy in which society lives off its capital, may in fact involve what amounts to not saving of unreproducible resources, so that their effective stocks are constantly expanded by the same family of developments that underlie the growth in real per capita income since the Industrial Revolution".

${ }^{14}$ Available at: <http://www.ggdc.net/maddison/maddison-project/home.htm, 2013 version>. Accessed on: 20 Sept. 2017.

${ }^{15}$ Regarding the importance of taking into account the energy and carbon embodied in goods and services imported and exported in the Brazilian case, see Machado et al. (2001).

${ }^{16}$ The nine countries are Chad, Guinea, Panama, Albania, Germany, Hungary, Poland, Kyrgyzstan, and Lithuania. Further research is necessary in order to explain the patterns of these countries that passed the test.
} 


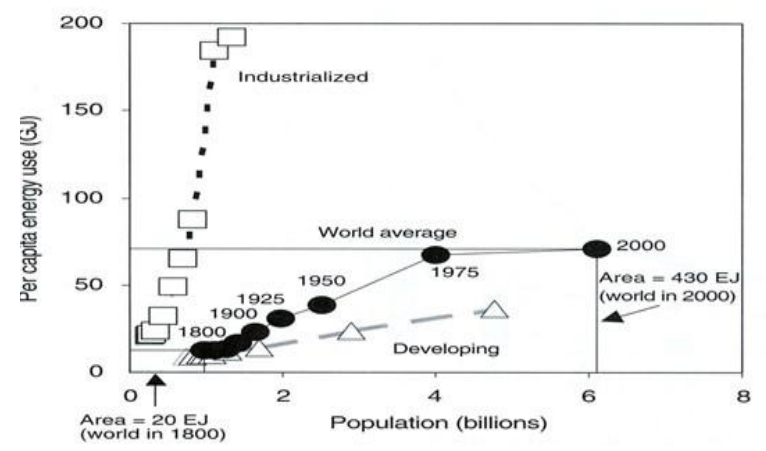

FIGURE 4.1 - Population growth (x axis) versus per capita energy use (y axis) in trajectories of 25-year intervals, from 1800 to 2000. Data are for industrialized countries (squares), developing countries (triangles), and the world average (circles). SOURCE: Grübler (2005)

to increase labour productivity through increases in per capita energy inflows. Contrary to the argument that a more efficient economic system tend to reduce energy consumption, the most highly capitalized countries (that is, developed countries) are those with the strongest trends in increasing per capita energy consumption ${ }^{17}$. It is possible to notice that primary per capita energy consumption measures the total energy demand of a country, divided by the population. It covers consumption by the energy sector itself, losses during transformation (for example, from oil or gas into electricity), energy distribution, and final consumption by end users (Eurostat, 2017). Thus, it includes all the sectors of economy.

Similar patterns are also seen when observing the consumption of materials over time. Krausmann et al. (2009) show that, during the 20th century, the upward trend in consumption of materials per capita was persistent and sharp (except for biomass). In addition to that, the authors also present the annual growth rates of major materials, population, GDP and total primary energy supply (TPES) for different periods covering the 20th century. Their data indicate that materials consumption per capita (DMC / cap) grew more slowly than income per capita (GDP / cap) and that the amount of material used per unit of GDP dropped. Therefore, today less material is used to produce each unit of economic value than in 1900 .

Nevertheless, this increased efficiency has not resulted in a decrease in the consumption of materials. These results are consistent with Georgescu-Roegen's $(1971 ; 1984)$ perspective and also with other studies evaluating the relation between economic efficiency and utilization of natural resources (Polimeni et al., 2008; Smil, 2014). Thus, both the energy consumption trajectory and the consumption of materials are in contradiction with Baumol's (1986) model implications.

\section{Not all relevant variables are market variables}

Given the fundamental importance of prices in neoclassical theory, one might think that the analysis proposed here is irrelevant to ascertain the empirical adequacy of the neoclassical framework. As prices are the main neoclassical indicators to assess the relevance of any production factor, many are prone to believe that the fact that energy and resource consumption has not yet declined and it is still rising

\footnotetext{
${ }^{17}$ The phenomenon by which energy efficiency gains stimulate the consumption of even more energy is known as Jevons's effect (Jevons, 1866; Alcott, 2005; Polimeni et al., 2008; York, 2010; Clement, 2011; Amado \& Sauer, 2012). The Jevons's effect raises serious doubts on efficiency discourse.
} 
means that these natural resources are not yet scarce enough ${ }^{18}$. From this perspective, the neoclassical view does not require decreasing energy resources as long as prices are not rising. Although energy and other biophysical resource consumption will eventually decline, positive economic growth with rising efficiency and increasing inflows could not be used as a rejection of the neoclassical hypothesis. For instance, in the clause on "Natural Resources" in the Concise Encyclopedia of Economics (Baumol \& Blackman, 2008), Baumol recognized the fact that the human consumption of a number of nonrenewable resources, as well as energy consumption, had grown exponentially since the 19th century. Is this enough to consider that natural resource inflows are irrelevant to evaluate the empirical adequacy of neoclassical framework?

The failure of this argument is to restrict the relevant evidence for the debate to the body of evidence that is usually taken as relevant by neoclassical approach, such as production factor prices. This way of formulating the problem of the economic analysis of natural resources has been quite influential. For example, in the bet between
Julian L. Simon and Paul E. Ehrlich, which is often used by proponents of the virtues of the free market as proof of the current economic system dynamics, the whole discussion begins and ends on the price observation $^{19}$. The assumption that today there are no conditions to refute any of the paradigms disputing how to describe the trajectories ${ }^{20}$ of the use of natural resources is another example of the tacit influence of the premise that only the types of evidence typically used by neoclassical tradition matter in assessing the empirical adequacy of economic theories used to explain these trajectories. This judgment is the result of considering the empirical analysis only in relation to the evidence as formulated by the orthodox theory, ignoring the possibility of extracting further necessary consequences of the framework used and eventually giving meaning to new types of evidence.

However, in evaluating a theory, it is not given a priori which body of evidence should count as relevant $^{21}$. There is no logical reason to restrict the analysis of the empirical adequacy of the established theory to the set of evidence that is usually taken as relevant by advocates of the questioned research

\footnotetext{
${ }^{18}$ Baumol (1986, p. 168): "We economists are prone to judge the abundance of resource by the behavior of its price. So long as demand for the item is not shifting downward and market prices are not markedly distorted by interferences such as government intervention, we expect that the real price of resource will rise as its remaining quantity declines, in accord with the classical theorem of Hotelling (1931)". Similarly, assuming everything else is constant, while prices fall, as has historically happened with natural resources, it should be expected that the demand rises.

${ }^{19}$ Desrochers (2015): “In 1980, economist Julian L. Simon challenged Paul R. Ehrlich, the biologist and author of the best-selling Population Bomb, to put his money where his catastrophist mouth was by staking $\$ 10,000$ on his belief that 'the cost of nongovernment controlled raw materials... will not rise in the long run', with the minimum period of time over which the bet could take place being one year. If, as Ehrlich believed, the store of valuable resources was absolutely finite and subject to ever increasing demand, the resources' price would rise. Simon, however, argued that in a market economy characterized by freely determined prices and secured property rights, a rise in the price of a valuable resource could only be temporary as it would provide incentives for people to look for more of it, to produce and use it more efficiently, and to develop substitutes. In the long run, even nonrenewable resources would become everless scarce as they are ultimately created by the always renewable and ever expanding human intellect". For Desrochers (2015), the bet showed that Malthusians are always wrong (with bold in the original). It is possible to notice that the idea that in the long term the effective availability of resources will always increase, even in a finite world in which the laws of thermodynamics apply, is the same idea defended by Baumol (1986).
}

${ }^{20}$ See note 4. 
program: if a set of evidence contradicts a theory and is a logical implication of that theory, why not treat this evidence as a real refutation of the theory? Restricting the analysis of a theory to the types of evidence usually evaluated by the orthodox theory is a way to imprison the proposed alternatives in an epistemological trap: while the alternatives are presented as a questioning of the mainstream framework, the evidence considered significant is only that that is subjectively considered relevant by practitioners of the mainstream framework, and not that that is objectively related to the assumptions and implications of the framework analyzed .

This situation creates an epistemological obstacle to the possibility of accessing evidence that may refute the mainstream theory. In this perspective, when taking into account the increasing flows of energy and materials, these are seen as an evidence of the need to worry about environmental issues, but not as a potential refutation of the neoclassical theory. Alternatively, if we do not restrict the relevant evidence field to the observed prices and develop the logical implications of the proposed models in order to ascertain the empirical consistency of these models (regardless if the implications are or not typical evidence), then it is possible to increase the conditions to submit the mainstream theory to critical tests.
In this case, if the neoclassical model tested repeatedly fails, there is reason to argue that the neoclassical technological optimism is not scientifically grounded. Clearly, there is an important difference between being a technological optimistic because theories and evidence support it - (Baumol's [1986] situation when we restrict analysis to usual neoclassical indicators, such as price and elasticity of substitution) -, and being a technological optimistic despite of what the relationship between our theoretical framework and available evidence says (new situation in which neoclassical assumptions are used to demonstrate the meaning and relevance of new evidence) $)^{22}$.

In fact, one of the strongest reasons for using alternative theories is to give meaning to new types of evidence. Refutation is not only important for demonstrating that a competing theory is wrong (or, more often, more limited than its rival(s) in relation to a particular problem or set of problems). Since all theoretical framework makes use of auxiliary assumptions in their empirical operationalization, very often it is possible to circumvent the refutation of the theory by discussing the plausibility and the relevance of auxiliary assumptions used in order to preserve the hard core of the theory (Lakatos, 1970). Therefore, we should not expect science to be develop based on definitive refutations, but recognize the

\footnotetext{
${ }^{21}$ The difficulty of establishing the relevant body of evidence to examine expectations derived from any advocated position was recognized by Georgescu-Roegen (1966, p. 243, author's emphasis): "Since there is no way of telling a priori what part of individual's knowledge does not bear upon a given expectation, E [Evidence] must stand for all knowledge of the individual at the time". Therefore, as it is not always obvious what body of evidence now available is relevant to analyze the empirical adequacy of the theory advocated by the individual, it is task of the analyst to make explicit any relevant existing links.

${ }^{22}$ Keynes (1921, p. 10, author's emphasis): “There is, first of all, the distinction between that part of our belief which is rational and that part which is not. If a man believes something for a reason which is preposterous or for no reason at all, and what he believes turns out to be true for some reason not known to him, he cannot be said to believe it rationally, although he believes in it and it is in fact true. On the other hand, a man may rationally believe a proposition to be probable, when it is in fact false. The distinction between rational belief and mere belief, therefore, is not the same as the distinction between true beliefs and false beliefs".
} 
importance of the "reasonable" falsification (Earp \& Trafimow, 2015).

However, the fact that there are no definitive refutations alone able to justify the abandonment of a paradigm (Kuhn, 1962) does not mean that they are not informative. The refutation of a model can be seen as a strategy to clarify the meaning of alternative approaches, since to refute a model is necessary to conceive the reality described by this model in ways not captured by it. Such an exercise necessarily requires us to contrast alternative material conceptions of reality. In the comparison outlined here, it was shown that it is economically informative to distinguish between intensive and extensive substitution of natural resources, since empirical results indicate that this distinction helps to explain natural resource use patterns prevalent in current society.

By demonstrating that increasing natural resources inflows are a refutation of Baumol's model (1986), we expose and specify the relevance of the distinction between funds and flows proposed by Geogescu-Roegen (1984). The increasing flows indicates that the establishment of more efficient equipment fund, as represented in the Baumol's model, requires the use of large amounts of total inflows. Also, it demonstrates that intensive substitution of natural resources, as assessed in accordance with the model proposed by Baumol (1986), has required extensive complementarity of natural resources, as indicated by trends in the global consumption of resources. In short, the available evidence makes the case that the increasing inflows of energy and materials has an economic significance that has not been captured by the orthodox model tested. Moreover, it corroborates the ecological economics arguments about the role of transformation of matter and energy to satisfy human needs (Cavalcanti, 2015).

Given the importance of intensive substitution for the entire neoclassical framework, it is reasonable to assume that the same methodological strategy used in the test of Baumol's model could allow to build critical tests in other neoclassical models. In particular, it should be possible to explore the assumptions underlying the use of the elasticity of substitution indicator in the context of sustainability debates. We use Baumol's model just as a first exercise to demonstrate that alternative theoretical concepts can be used to build critical tests of the neoclassical theory of the substitution of natural resources.

\section{Conclusion}

Using Baumol's (1986) model and the distinction between funds and flows proposed by Georgescu-Roegen $(1971 ; 1984)$, we derive an analytical implication that signalizes towards the rejection of the hypothesis of continuing expansion of finite resources. The results also suggest the need to reinterpret the processes triggered by the Industrial Revolution: everything indicates that growth economies are only possible while it is viable to increase natural resource inflows. The significant efficiency gains in the last two centuries have not been sufficient to offset the increased demand for high quality natural resources, especially the limited and exhaustible stocks with high potential to be converted in motive power, such as oil.

The reduction of natural resource prices in the long run has been the result of increased exploration and supply of non-renewable resources, and not because the economic system has been successful 
in reducing natural resource dependency. Viewing the economy simply as a circulation of money has prevented recognition of the outstanding contribution of natural resources to the observed trajectory of productivity gains (Brown \& Ulgiati, 2011). Technological progress has allowed the economic system to become increasingly complex, differentiated and efficient, but it intensified the reliance on natural resources, as the tendencies involving per capita energy and material consumption indicate. Therefore, the results and discussion of this paper support current critics of the capitalist growth trajectories (Marques, 2015).

\section{Acknowledgments}

Issues directly related to this work were systematically discussed with Blake Alcott, whom we thank. We would like to thank both reviewers for their insightful comments on the paper, as these comments led us to improve the work. Obviously, any errors are our own. The first author acknowledges the financial support of PNPD-CAPES (Programa Nacional de Pós-Doutorado - Coordenação de Aperfeiçoamento de Pessoal de Nível Superior) in the pursuit of a postdoctoral research; the second author acknowledges the financial support of $\mathrm{CNPq}$ in the pursuit of a doctoral research. We would also like to thank Javier Buitrago, $\mathrm{PhD}$, for the mathematical help.

\section{References}

Alcott, B. Jevon's Paradox. Ecological Economics, 54(1), 9-21, 2005. doi:10.1016/j.ecolecon.2005.03.020
Amado, N. B.; Sauer, I. L. An Ecological Economic Interpretation of the Jevons Effect, Ecological Complexity, 9, 2-9, 2012. doi: 10.1016/j.ecocom.2011.10.003

Barnett, H. J.; Morse, C. Scarcity and Growth - The Economics of Natural Resource Availability. Washington, DC, USA: Resources for the Future, 1963.

Baumol, W. J. On the Possibility of Continuing Expansion of Finite Resources. Kyklos, 39, 167-179, 1986. doi: 10.1111/ j.1467-6435.1986.tb00766.x

Baumol, W. J.; Blackman, S. A. B. Natural Resources. In: The Concise Encyclopedia of Economics. Library of Economics and Liberty, 2008. Retrieved January 13, 2014 from: http:/www.econlib.org/library/Enc/NaturalResources.html

Bithas, K.; Kalimeris, P. The Material Intensity of Growth: Implications from the Human Scale of Production. Social Indicators Research, 1-19, 2016. doi: 10.1007/s11205016-1401-7.

Brown, M. T.; Ulgiati, S. Understanding the global economic crisis: A biophysical perspective, Ecological Modelling, 223(1), 4-13, 2011. doi: 10.1016/j.ecolmodel.2011.05.019.

Carmona, M.; Feria, J.; Golpe, A. A.; Iglesias, J. Energy consumption in the US reconsidered. Evidence across sources and economic sectors. Renewable and Sustainable Energy Reviews, 77, 1055-1068, 2017. doi: 10.1016/j. rser.2016.11.227.

Cavalcanti, C. Socio-Environmental Thinking and Ecological Economics: a New Perspective to Think About Society. Desenvolvimento e Meio Ambiente, 35, 169-178, 2015. doi: 10.5380/dma.v35i0.43545.

Chen, J.; Wang, Y.; Song, M.; Zhao, R. Analyzing the decoupling relationship between marine economic growth and marine pollution in China. Ocean Engineering, 137, 1-12, 2017. doi: 10.1016/j.oceaneng.2017.03.038

Clement, M. T. The Jevons paradox and anthropogenic global warming: A panel analysis of state-level carbon emissions in the United States, 1963-1997. Society \& Natural Resources, 24(9), 951-961, 2011. doi: 10.1080/08941920903421133

Conover, W. J. Practical nonparametric statistics, 1980. New York: Wiley. 
Daly, H. E. Operationalizing Sustainable Development by Investing in Natural Capital. In: Jansson, A-M, Hammer, M.; Folke, C.; Costanza, R. (Eds.). Investing in Natural Capital: The Ecological Economics Approach to Sustainability, Washington, D.C.: Island Press, 1994.

Daly, H. Georgescu-Roegen versus Solow/Stiglitz, Ecological Economics, 22(3), 261-266, 1997a.

Daly, H. Reply to Solow/Stiglitz. Ecological Economics, 22(3), 271-273, $1997 b$.

Desrochers, P. The Simon-Ehrlich wager 25 years on - As the famous environmentalist bet showed, Malthusians are always wrong. Spiked-online, 29 September 2015. Available at: $<$ http://www.spiked-online.com/newsite/article/the-simonehrlich-wager-25-years-on/17482\#.WdAAkjCnGM8>

Earp, H. N. S.; Romeiro, A. R. The Entropy Law and the Impossibility of Perpetual Economic Growth. Open Journal of Applied Sciences, 5, 641-650, 2015. doi: 10.4236/ ojapps.2015.510063

Earp, B. D.; Trafimow, D. Replication, falsification, and the crisis of confidence in social psychology. Frontiers in Psychology, 6, 1-11, 2015.

EIA. Data retrieved (15/04/2015), from Energy Information Administration (EIA) database, 2015. Available at: $<$ http://www.eia.gov/cfapps/ipdbproject/iedindex3.cfm?tid $=44 \&$ pid $=45 \&$ aid $=2 \&$ cid=regions \&syid $=1980 \&$ eyi$\mathrm{d}=2011 \&$ unit $=$ MBTUPP $>$

EUROSTAT. Glossary: Primary energy consumption, 2017. Available at: $<$ http://ec.europa.eu/eurostat/statistics-explained/index.php/Glossary:Primary_energy_consumption>

Feyerabend, P. Problems of Empiricism. In: Colodny, R. (Ed.). Beyond the Edge of Certainty. Pittsburgh: University of Pittsburgh Press, pp. 145-260, 1965.

Gauthier, T. D. Detecting Trends Using Spearman's Rank Correlation Coefficient. Environmental Forensics, 2, 359362, 2001.

Georgescu-Roegen, N. The Nature of Expectation and Uncertainty. In: Georgescu-Roegen, N. Analytical Economics - Issues and Problems. Cambridge, Massachustts: Harvard University Press, 1966.
Georgescu-Roegen, N. The entropy law and the economic process. Cambridge, Mass.: Harvard University Press, 1971.

Georgescu-Roegen, N. Feasible Recipes Versus Viable Technologies. Atlantic Economic Journal, 12(1), 21-31, 1984.

Giampietro, M.; Mayumi, K. The Jevons Paradox: The Evolution of Complex Adaptive Systems and the Challenge for Scientific Analysis. In: Polimeni, J. M.; Mayumi, K,; Giampietro, M.; Alcott, B. The Jevons Paradox and the Myth of Resource Efficiency Improvements. London, Sterling: Earthscan, 2008.

Grübler, A. Transitions in Energy Use. In: Cutler, J. C. (editor-in-chief). Encyclopedia of Energy. Amsterdam: Elsevier Academic Press, 2005.

Hotelling, H. The Economics of Exhaustible Resources. The Journal of Political Economy, 39(2), 137-175, 1931.

Jevons, W. S. The Coal Question: An Inquiry Concerning the Progress of the Nation, and the Probable Exhaustion of Our Coal-mines, 1866. London: Macmillan.

Kalimeris, P.; Richardson, C.; Bithas, K. A meta-analysis investigation of the direction of the energy-GDP causal relationship: implications for the growth-degrowth dialogue. Journal of Cleaner Production, 67, 1-13, 2014. doi: 10.1016/j.jclepro.2013.12.040

Keynes, J. M. A treatise on probability, London: MacMillan and Company, 1921.

Krausmann, F.; Gingrich, S.; Eisenmenger N.; Erb, K. H.; Haberl, H.; Fisher-Kowalski, M. Growth in global materials use, GDP and population during the 20th century, Ecological Economics, 68(10), 2696-2705, 2009.

Kuhn, T. S. The structure of scientific revolutions, 1962. Chicago: University of Chicago Press.

Lakatos, I. Falsification and the methodology of scientific research programmes. In: Lakatos, I.; Musgrave, A. (Eds.). Criticism and the growth of knowledge, London: Cambridge University Press, pp. 91-196, 1970.

Machado, G.; Schaeffer, R.; Worrell, E. Energy and carbon embodied in the international trade of Brazil: an input-output approach, Ecological Economics, 39(3), 409-424, 2001. doi: 10.1016/S0921-8009(01)00230-0 
Maddison, A. Data retrieved (20/09/2017) from Home Maddison database, 2017. Available at: $<$ http://www.ggdc. net/maddison/maddison-project/home.htm, 2013 version>.

Marques, L. Capitalismo e colapso ambiental. Campinas, SP: Editora da Unicamp, 2015.

Neumayer, E. Weak versus Strong Sustainability: Exploring the Limits of Two Opposing Paradigms. Cheltenham, UK; Northampton, MA, USA: Edward Elgar, 2003.

Nordhaus, W. D.; Tobin, J. Is Growth Obsolete? In: Economic Growth, National Bureau of Economic Research, General Series No. 96, New York, pp.1-80, 1972.

Polimeni, J. M.; Mayumi, K.; Giampietro, M.; Alcott, B. The Jevons Paradox and the Myth of Resource Efficiency Improvements. London, Sterling: Earthscan, 2008.

Romeiro, A. Sustainable development: an ecological economics perspective. Estudos Avançados, 26(74), 65-92, 2012. doi: 10.1590/S0103-40142012000100006

Schumpeter, J. A. Science and Ideology, The American Economic Review, 39(2), 346-359, 1949.
Smil, V. Making the modern world: Materials and Dematerialization. John Wiley \& Sons Ltd, The Atrium, Southern Gate, Chichester, West Sussex, PO19 8SQ, United Kingdom, 2014.

Solow, R. The economics of resources or the resources of economics. American Economic Review, 64(2), 1-14, 1974.

Solow, R. Georgescu-Roegen versus Solow-Stiglitz. Ecological Economics, 22(3), 267-268, 1997.

Sontag, R. E; Borgnakke, C.; Van Wylen, G. Fundamentals of Thermodynamics. New York: Wiley, 2003.

Yue, S.; Pilon, P.; Cavadias, G. Power of the Mann-Kendall and Spearman's rho tests for detecting monotonic trends in hydrological series. Journal of Hydrology, 259, 254-271, 2002.

York, R. Three lessons from trends in $\mathrm{CO} 2$ emissions and energy use in the United States. Society \& Natural Resources, 23(12), 1244-1252, 2010. 